\title{
A economia das firmas cooperadas e a análise antitruste
}

\author{
Luiz A. Esteves ${ }^{* *}$
}

\begin{abstract}
Resumo
A literatura econômica tem despendido décadas de esforço analítico para fornecer evidências teóricas e empíricas acerca das diferenças de comportamento entre as firmas gerenciadas pelo capital (firmas capitalistas convencionais) e firmas gerenciadas pelo trabalho (inclui as cooperativas e associações de profissionais), principalmente no que diz respeito aos seus objetivos. As firmas capitalistas convencionais objetivam a maximização dos lucros, enquanto que as firmas cooperadas objetivam a estabilidade do emprego e do produto. A política antitruste tem replicado o mesmo tratamento despendido às firmas capitalistas convencionais para os casos envolvendo as firmas cooperadas. Tal decisão pode aumentar a probabilidade de ocorrências de erros do tipo I e do tipo II. Esse problema se torna menor quando os casos envolvem "falsas cooperativas". Em termos de política pública, a conclusão do presente artigo é de que uma concentração ou coordenação entre cooperados de fato ou profissionais não é, per se, condição necessária e suficiente para causar dano concorrencial. As especificidades destes tipos de organizações demandam análise específica e a aplicação da regra da razão. Finalmente, o artigo fornece uma proposta de filtro para distinção entre firmas cooperadas de fato e de cartéis disfarçados de cooperativas.
\end{abstract}

Palavras-chave: Antitruste; Concorrência; Cooperativas; Monopólios; Cartéis.

\begin{abstract}
Democratic firms, labor-managed firms, and antitrust analysis

The economic literature has spent decades on analytical analysis in order to provide theoretical and empirical evidence on the behavioral differences between firms managed by capital (conventional capitalist firms) and firms managed by labor (including cooperatives and professional associations), mainly with respect to their goals. Conventional capitalist firms aim to maximize profits, while the objectives of cooperative firms are employment and output stability. The antitrust policy has replicated the same treatment used to analyze conventional capitalist firms in order to analyze cooperative firms. Such a decision can increase the probability of type I and type II errors. The problem is less severe when the antitrust cases involve "false cooperatives". In terms of public policy, the article concludes that a concentration or coordination between cooperatives or professional associations is not, per se, a necessary and sufficient condition to cause competitive harm. The idiosyncrasies of these types of organizations require specific analysis and application of the rule of reason. Finally, the article provides a method to filter and to distinguish between real and "false cooperative" behaviors.
\end{abstract}

Keywords: Antitrust; Competition; Cooperatives; Monopolies; Cartels JEL K21, P13, D42.

\footnotetext{
* Artigo recebido em 14 de setembro de 2014 e aprovado em 8 de agosto de 2015. O autor é grato aos comentários e sugestões dos pareceristas anônimos. Os erros e omissões são responsabilidade exclusiva do autor.

** Professor do Departamento de Economia da Universidade Federal do Paraná (UFPR) / Bolsista Produtividade em Pesquisa do Conselho Nacional de Desenvolvimento Científico e Tecnológico (CNPq), Curitiba, PR, Brasil. E-mail: esteves@ufpr.br.
} 


\section{Introdução}

Um dos principais desafios das autoridades antitruste ao redor do mundo é

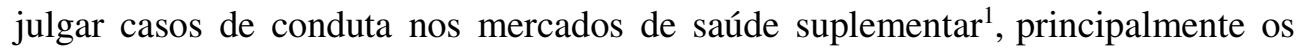
casos que envolvem condutas anticompetitivas por parte de associações e cooperativas de profissionais médicos. Em termos gerais, as investigações e punições administrativas nestes mercados tendem a se concentrar em três diferentes tipos de condutas anticompetitivas: (i) a aplicação de tabelas de preços em negociações entre os diferentes elos da cadeia de saúde suplementar²; (ii) as cooperativas de especialidades médicas - que em geral envolve a constituição de uma pessoa jurídica, derivada da reunião de médicos de determinada especialidade - para negociar com operadoras de plano de saúde; e (iii) a unimilitância, que envolve a exigência na exclusividade da oferta de serviços por um médico, ou grupo de médicos, para algum outro agente no mercado de saúde complementar (hospital, operador de planos de saúde ou cooperativa médica $)^{3}$.

O tema recebe atenção crescente ao redor do mundo por conta da rápida reestruturação destes mercados nas últimas décadas, motivada principalmente pelos custos crescentes associados aos tratamentos médicos, seja por conta da crescente introdução de inovações tecnológicas, seja por conta da rigidez da oferta de profissionais altamente especializados das áreas médicas (Hsiao, 1995). O desdobramento nestes casos foi o crescimento exponencial do mercado de financiamento de saúde suplementar (o primeiro elo da cadeia da saúde complementar, constituído pelos consumidores demandantes e pelas operadoras ofertantes de planos e seguros de saúde), ou seja, da compra e venda de seguros.

Os seguros são acionados quando os consumidores demandam serviços médicos no segundo elo da cadeia de saúde suplementar, formado pelos pacientes demandantes e pelos médicos ofertantes dos serviços. Contudo, os honorários pela remuneração dos serviços médicos neste mercado são negociados entre os médicos e as operadoras ofertantes de planos e seguros de saúde. A implicação é que os honorários médicos estarão sujeitos a um processo de barganha, em que a parte que dispuser de maior poder de mercado (leverage) terá maior probabilidade de captura de frações maiores dos lucros gerados ao longo da cadeia de saúde suplementar. Por conta disso, a prática autônoma entre os profissionais da medicina tem se reduzido significativamente em favor de estruturas organizacionais cooperadas ou

(1) A Agência Nacional de Saúde Complementar (ANS) define saúde complementar (ou assistência suplementar da saúde) como a atividade que envolve a operação de planos privados de assistência à saúde sob a regulação do Poder Público (Brasil, 2009, p. 84).

(2) Uma apresentação detalhada de cada um dos elos da cadeia do mercado de saúde suplementar é fornecida por Hsiao (1995).

(3) A edição da série Cadernos do Cade para o ano de 2015 (Cade, 2015), intitulada "Mercado de Saúde Complementar: Condutas" traz um levantamento pormenorizado da estrutura, das imperfeições de mercado e da jurisprudência do órgão envolvendo casos de conduta para o mercado de saúde complementar. 
associativas, de forma a eliminar potenciais assimetrias na barganha (Goldberg, 2006). Tal argumento fornece as bases para a tese de defesa das cooperativas médicas junto às autoridades antitruste em casos de condutas anticompetitivas: a tese do poder compensatório, que será discutida em detalhes ao longo do artigo.

Por outro lado, há um conjunto de argumentos econômicos que fornecem as bases para a acusação de conduta anticompetitiva por parte de cooperativas médicas. Tais argumentos são satisfatoriamente abordados e resumidos em um artigo de opinião, publicado no Jornal Folha de S. Paulo de 13 de novembro de 2014, intitulado "Cartel é prejudicial à saúde", de autoria dos economistas Gesner Oliveira e Roland Saldanha e dos advogados Paolo Mazzucato e Marcela Altale. Os principais argumentos são: (i) não há poder de mercado a ser compensado, uma vez que a concentração de mercado (geralmente mensurada por algum índice de concentração, tal como HHI, C4, etc.) no mercado de operadores de planos de saúde é pequena; (ii) a maioria das cooperativas de especialidades médicas condenadas pelo Cade (autoridade antitruste brasileira) está localizada em grandes centros urbanos, onde a oferta de profissionais altamente especializados é bem maior do que em regiões menos densamente povoadas ${ }^{4}$; e (iii) a tese do poder compensatório, em que algum grau de concentração de mercado poderia até mesmo melhorar a concorrência, tem seus efeitos pouco conhecidos na literatura econômica.

Não há dúvidas de que muito dos casos levados às autoridades de concorrência, que recaiam suspeitas sobre a conduta anticompetitiva por parte de associações ou cooperativas de profissionais, envolvem tanto questões de lide privada $^{5}$, quanto o falseamento da atividade cooperada por parte de cartéis. Contudo, a identificação e detecção econômica de cartéis não é algo trivial e muitas técnicas (especialmente filtros comportamentais) têm sido desenvolvidas para superar tais dificuldades $^{6}$. O mesmo ocorre nos casos em que as autoridades da concorrência devem filtrar se uma agremiação de profissionais está operando como uma organização cooperada, ou se na realidade trata-se de um cartel disfarçado de cooperativa. A tarefa também não é simples, mas o primeiro passo neste sentido é a melhor compreensão da economia das firmas cooperadas - um tema já bem desenvolvido na literatura econômica e pouco explorado na análise econômica da concorrência.

(4) A ideia central neste argumento é de que as cooperativas médicas teriam como objetivo agir de forma colusiva para garantir que os honorários nos grandes centros urbanos, onde a oferta de profissionais especializados é maior, se mantenham artificialmente altos. Tal conduta teria como implicação o incentivo perverso de desestimular os médicos a se deslocarem para áreas menos densamente povoadas do país.

(5) Em alguns casos, uma barganha malsucedida entre as partes privadas, traz como implicação uma denúncia junto à autoridade antitruste.

(6) Para uma discussão pormenorizada sobre o tema, ver Harrington (2008). 
Uma das limitações da análise econômica antitruste é tentar reproduzir, na íntegra, o mesmo arcabouço analítico comumente utilizado em relações competitivas (horizontais ou verticais, de concentração ou de conduta) envolvendo empresas comerciais (a partir daqui denominadas firmas capitalistas convencionais) para o caso de relações competitivas envolvendo associações, cooperativas de profissionais ou empresas gerenciadas pelo fator trabalho (a partir daqui denominadas firmas cooperadas $^{7}$ ).

Seria desejável que as autoridades e os profissionais da área de política da concorrência analisassem os casos de concentração e conduta por parte de cooperativas ou associações de profissionais tomando como referência a literatura econômica específica sobre o tema, aqui denominada de Economia das Firmas Cooperadas (ou Economia das LMFs ou Economia da Firma Democrática). Assim como todos os demais temas em Economia, há controvérsia entre os principais autores desta linha de pesquisa, porém todos parecem concordar em um aspecto: os incentivos das firmas capitalistas convencionais são completamente diferentes das firmas cooperadas.

A literatura econômica tem despendido décadas de esforço analítico para fornecer argumentos teóricos e evidências empíricas minimamente satisfatórias para as seguintes questões: (i) Qual a diferença entre o capital contratar o trabalho e o trabalho contratar o capital? (ii) Por que é mais comum encontramos o capital contratando o trabalho e não o contrário? (iii) A firma capitalista convencional é mais eficiente que a firma cooperada? (iv) As firmas cooperadas são capazes de suavizar ciclos econômicos?

Dow \& Putterman (2000) sintetizam a relevância do tema, originalmente desenvolvido por Benjamin Ward, na segunda metade da década de 1950 (Ward, 1958), nos seguintes termos:

A question of fundamental theoretical and policy importance is why when more than a few workers engage in a joint enterprise, they are typically hired by providers of financial resources (or by agents of the latter), rather than organizing the enterprise themselves and contracting with outsiders for the supply of capital (Dow; Putterman, 2000, p. 320-321).

Como já mencionado, o tema é repleto de controvérsias entre os vários estudiosos do assunto, mas um segundo ponto também parece ser unânime entre os economistas: em equilíbrio walrasiano, com mercados perfeitamente competitivos e completos, com informação perfeita e ausência de externalidades, com completa ausência de imperfeições de mercado, não haveria qualquer diferença de incentivos

(7) Autores de tradição neoclássica e novo-institucionalista denominam tais tipos de empresas como $L M F s$ (labor-managed firms). Já economistas de tradição marxista, tais como os marxistas analíticos e economistas radicais denominam tais empresas como firmas democráticas. 
entre uma firma capitalista convencional de uma firma cooperada (Dow, 1986, 1993; Drèze, 1976, 1989), ou seja, seria completamente indiferente o capital contratar o trabalho, ou o trabalho contratar o capital (Samuelson, 1957).

Do parágrafo acima podemos concluir que a única situação na qual podemos colocar firmas capitalistas convencionais e firmas cooperadas em condições de similaridade analítica é exatamente quando a análise antitruste (ou qualquer outra política pública ou regulatória) é teoricamente irrelevante e desnecessária. Sobre esse ponto, é importante lembrar que todo o projeto de pesquisa envolvendo a análise de estrutura-conduta-desempenho (E-C-D) foi construído tendo em mente os incentivos que norteiam as ações das firmas capitalistas convencionais, ou seja, a firma maximizadora de lucros. Este paradigma criou as bases da Economia Antitruste e o referencial analítico para a Política da Concorrência. Isso não significa que os cooperados também não queiram auferir o maior rendimento possível, mas neste caso, como veremos adiante, os interesses individuais são subordinados ao interesse coletivo. Em termos econômicos, isso significa dizer que nestes casos os recursos não são alocados pela lógica descentralizada dos mercados, denominada por Adam Smith como "mão invisível”, mas pela lógica da ação coletiva (Olson, 1999; Ostrom, 1990).

O objetivo deste artigo não é fazer qualquer inferência sobre qual dos modelos de negócio é o mais eficiente, mas entre outras coisas, explicitar que são duas formas diferentes e empiricamente distintas de conduzir os negócios, principalmente no que diz respeito às estratégias de investimento, emprego e produção. Bowles e Gintis (1993), expõem parte das diferenças nos seguintes termos:

A more even-handed treatment of the capitalist versus the democratic firm identifies the market-failures that both types of firms face and then analyzes their comparative performance in handling these market failures. We here follow such a strategy, identifying failures in labor and capital markets inherent in all market economies, to which capitalist and democratic firms can be expected to respond in systematically different ways (Bowles; Gintis, 1993, p. 76).

Para Bowles e Gintis (1993), um dos pontos nodais na distinção do comportamento, dos incentivos e das reações a choques de oferta ou demanda se dá pelo fato de como cada um dos tipos de empresas lidam com o problema de agência (problema de agente-principal).

Posto isto, é desnecessário mencionar que a interação estratégica entre duas firmas capitalistas convencionais será diferente das interações entre duas firmas cooperadas, que por sua vez será diferente da interação estratégica entre uma firma capitalista convencional e outra cooperada. A ideia central do presente artigo é alertar para o fato de que o uso de referencial analítico inadequado para a análise de 
atos de concentração e de conduta envolvendo firmas cooperadas pode aumentar significativamente as probabilidades de ocorrência de Erro do Tipo I (julgar o réu culpado, quando na realidade é inocente) e Erro do Tipo II (julgar o réu inocente, quando na realidade é culpado). Logo, faz-se necessário o aprimoramento de uma metodologia de filtro econômico comportamental para melhor a identificação e a distinção entre situações nas quais uma agremiação de profissionais está operando como uma organização cooperada ou como um cartel disfarçado de cooperativa. Portanto, o objetivo central do presente artigo é coletar na literatura econômica um conjunto de aspectos teóricos e fatos estilizados acerca do comportamento estratégico esperado de firmas cooperadas de modo a fornecer uma proposta de filtro comportamental.

O presente artigo é dividido em cinco seções, incluindo a presente introdução. A primeira seção é dedicada a analisar as noções de propriedade, controle e exercícios de direitos residuais sobre as firmas, bem como tais noções são utilizadas para identificar e classificar as organizações entre firmas capitalistas convencionais e firmas cooperadas. A segunda seção apresenta uma discussão sobre a teoria e a prática da determinação do produto e do emprego em firmas capitalistas tradicionais e firmas cooperadas. A terceira seção trata da questão da lógica da ação coletiva e como esta se diferencia da lógica dos mercados descentralizados e da "mão invisível". A quarta seção discute a relevância da barganha e do poder compensatório na análise antitruste envolvendo firmas cooperadas. A última seção é dedicada às conclusões e considerações finais.

\section{Controle e propriedade das firmas}

Nesta seção buscar-se-á elucidar de forma mais rigorosa a distinção entre firmas capitalistas convencionais e firmas cooperadas. Neste sentido, seguiremos a mesma noção desenvolvida por Dow e Putterman (2000), ou seja, a distinção fundamental entre tais tipos de firmas repousa sobre "quem controla" a firma, ao invés de quem "tem sua propriedade" ou quem "detém seus direitos residuais".

Um segundo passo é tentar compreender qual o significado de "controle" de uma firma. A literatura econômica Novo Institucionalista sugere que uma firma surge quando vários agentes se unem em uma atividade produtiva conjunta, ou seja, a execução de manufatura e comercialização de um determinado bem ou serviço envolve a utilização de vários insumos complementares. Poderíamos então interpretar uma firma como um conjunto de contratos de compra e venda de insumos necessários para produzir e comercializar bens e serviços. Contudo, sabemos que é

(8) Aqui a expressão "direitos residuais" é utilizada como uma tradução livre da expressão inglesa residual claims. Na Economia, o residual claimant é o agente econômico que precifica o custo de oportunidade e aufere os lucros econômicos da atividade econômica exercida pela firma, ou seja, a receita líquida livre de todos os custos necessários para remunerar os demais fatores de produção. 
impossível especificar nas cláusulas de um contrato todas as possíveis contingências incorridas nas relações entre os agentes da firma (Williamson, 1985; Hart, 1995). Portanto, o foco sobre o "controle" da firma se justifica sobre os seguintes termos:

If firms are production coalitions marked by incompleteness of contracts, it is crucial to determine who is entitled to fill in the details of these ongoing interactions. This motivates our definition of a conventional or capitalist firm as one where control rights are held by suppliers of capital or equity finance, and of labor-managed firms (LMFs) as ones where control rights are held by suppliers of labor (Dow; Putterman, 2000, p. 321).

Como observado acima, o agente encarregado para exercer o controle da firma terá a prerrogativa de preencher os detalhes das interações em curso, ou seja, arcará com a missão de, em um ambiente de informação assimétrica e problemas de agência, desenhar os incentivos para extrair o melhor desempenho e produtividade dos demais agentes. Políticas de monitoramento de desempenho e remuneração dos trabalhadores (carrots \& sticks), por exemplo, é um dos vários mecanismos utilizados pelas firmas neste sentido (Shapiro; Stiglitz, 1984; Bowles, 1985; Leonard, 1987). Políticas contratuais focadas em relacionamentos de longo prazo, baseadas na reputação advinda de um histórico de várias interações, também são utilizadas como meios de mitigar os problemas decorrentes de seleção adversa (Katz, 1986; Rebitzer, 1987; Abraham; Prosch, 2000).

Já a propriedade da firma é representada por Dow e Putterman (2000) como uma cesta de direitos incluindo direitos residuais (residual claims), direito de controle e a propriedade dos ativos físicos. A complicação em diferenciar firmas capitalistas convencionais de firmas cooperadas em termos de propriedade é que nem sempre todos os elementos desta cesta de direitos pertencem a um único agente. Por exemplo, cooperativas podem ser constituídas sem que nenhum de seus cooperados detenha a propriedade total ou parcial sobre os ativos físicos utilizados no processo produtivo. Contratos de locação financeira ou arrendamento mercantil (leasing) são mecanismos clássicos de viabilidade da divisão de propriedade e controle de ativos físicos.

Um dos argumentos comumente utilizados na literatura para justificar uma suposta superioridade das firmas capitalistas convencionais frente às firmas cooperadas é o de que o exercício do controle é mais eficiente quando exercido pelo proprietário do capital. O argumento é relativamente simples: o uso dos ativos físicos também envolve custos de controle e monitoramento, assim como o desempenho dos trabalhadores, bem como a relação entre trabalhadores e equipamento de capital. Portanto, o fato de um único agente controlar todas as contingências não especificadas contratualmente nas relações da firma seria um mecanismo de economia de custos (inclusive custos de transação) e de eficiência organizacional. 
Outro ponto a ser considerado é o de que um agente pode não deter o controle da firma, tampouco deter a propriedade de seus ativos físicos, mas deter ao menos parte de seus direitos residuais, ou seja, ser um (ou um dos) residual claimant(s) da firma. Um exemplo bem comum são os planos de participação de lucros e resultados. Cabe também destacar que tais mecanismos são geralmente utilizados como incentivos por quem exerce o controle da firma (Blanchflower; Oswald; Sanfei, 1996; Hildreth; Oswald, 1997).

\section{Emprego e produto: teoria e prática}

Como já mencionado anteriormente, Benjamin Ward (Ward, 1958) foi o primeiro economista a tratar das diferenças de objetivos e, por conseguinte, de determinação do emprego, do produto e dos salários entre as firmas capitalistas convencionais e as firmas cooperadas. Posteriormente, autores como Domar (1966), Vanek (1970) e Meade (1972) contribuíram com versões mais sofisticas do argumento original.

Em termos gerais, pode-se expor o argumento nos seguintes termos ${ }^{9}$ : imaginemos uma tecnologia especificada na forma de uma função de produção $Q(L)$ estritamente côncava, onde $Q$ é o nível de produto e $L$ é o insumo trabalho, que também é o número de trabalhadores da firma capitalista convencional (que denominaremos como $L^{F}$ ) ou de membros da firma cooperada (que denominaremos como $L^{C}$ ). A produção implica em um custo fixo igual a $C$ e a mercadoria é vendida em um mercado competitivo ao preço de $P$. Adicionalmente, assumimos que: (i) o objetivo da firma capitalista convencional é a maximização de lucros; (ii) o objetivo da firma cooperada é a maximização da receita líquida per capita (dividendos per capita) para seus membros associados; e (iii) a firma capitalista convencional apresenta lucro econômico no curto prazo.

O lucro da firma capitalista convencional é igual a $p Q\left(L^{F}\right)-C-w L^{F}$, onde $w$ é o nível de salário, determinado no mercado de trabalho, pago ao insumo trabalho. Já a receita líquida per capita (dividendos per capita) da firma cooperada é igual a $\left[p Q\left(L^{C}\right)-C\right] / L^{C}$. A firma capitalista convencional escolherá um nível de produto que maximize seu lucro, de forma que a condição de primeira ordem encontrada é igual a $w=p Q^{\prime}\left(L^{F}\right)$, onde o salário é igual ao produto marginal do trabalho. Já a firma cooperada escolherá um número de membros $L$ que maximize a receita líquida per capita (dividendos per capita) de seus associados, de forma que a condição de primeira ordem é igual a $\left[p Q\left(L^{C}\right)-C\right] / L^{C}=p Q^{\prime}\left(L^{C}\right)$, onde o dividendo per capita é igual ao produto marginal do trabalho.

Para que a firma capitalista convencional tenha lucro de curto de prazo, fazse necessário que sua receita líquida por trabalhador seja superior ao salário pago a

(9) Aqui utilizamos uma modelagem similar a Bonin, Jones e Putterman (1993). 
cada trabalhador (que por sua vez é igual ao produto marginal do trabalho), ou seja, $\left[p Q\left(L^{F}\right)-C\right] / L^{F}>w=p Q^{\prime}\left(L^{F}\right)$. Comparando esta última equação com a última equação apresentada no parágrafo anterior, o leitor perceberá que só será possível a firma cooperada obter lucro caso $p Q^{\prime}\left(L^{C}\right)>p Q^{\prime}\left(L^{F}\right)$. Para tanto, dada a estrita concavidade da função produção, tal resultado só será alcançado caso $L^{C}<L^{F}$. Contudo, se não houvesse lucros de curto de prazo, o nível de produção e emprego seria indiferente entre a firma capitalista convencional e a firma cooperada.

A interpretação de tais modelos sugere que, sob quaisquer situações de equilíbrio não walrasiano, as firmas cooperadas seriam menos eficientes que as firmas convencionais capitalistas, pois tenderiam a empregar menos mão de obra e produzir menores quantidades de bens e serviços. Adicionalmente, responderiam perversamente a mudanças de preços, reduzindo a produção quando os preços aumentassem e vice-versa (Bowles; Gintis, 1993, p.75), ou seja, teriam uma curva de oferta negativamente inclinada. Como apontado por Bonin, Jones \& Putterman (1993), a robustez de tal resultado teórico chamou a atenção de vários pesquisadores, que mostraram posteriormente que tal resultado não seria generalizado para o caso de função de produção com múltiplos insumos e para o caso de empresas multiproduto (Bonin; Fukuda, 1986; Domar, 1966). Adicionalmente, caso as horas de esforço de trabalho possam variar em resposta a variações de preço, a curva de oferta de curto prazo para uma empresa uniproduto também poderá ser positivamente inclinada (Ireland; Law, 1981). Outros refinamentos deste mesmo modelo foram capazes de encontrar resultados teóricos mais condizentes com os fatos estilizados encontrados na literatura empírica ${ }^{10}$. Alguns destes resultados empíricos catalogados por Bonin, Jones e Putterman (1993) podem ser sumarizados conforme abaixo:

- Firmas cooperadas tendem a buscar a manutenção da estabilidade do emprego e do produto em face às variações de preços e demais choques, ou seja, uma curva de oferta praticamente inelástica;

- Firmas cooperadas tendem a operar com razões capital-trabalho inferiores àquelas observadas entre as firmas capitalistas convencionais;

- A formação de firmas cooperadas tende a ocorrer em ondas com períodos de duração inferiores aos dos ciclos econômicos;

- Uma vez estabelecida e em operação, firmas cooperadas tendem a ser mais resistentes (maiores taxas de sobrevivência) que firmas capitalistas convencionais;

- Algumas firmas cooperadas surgem motivadas pela proteção e manutenção do emprego. Outras são constituídas para providenciar um ambiente no qual a interação entre os trabalhadores seja cooperativa e não alienante;

(10) Bonin, Jones e Putterman (1993) fornecem um levantamento bibliográfico das literaturas teórica e empírica. A discussão sobre os desdobramentos do modelo de Ward (1958) é abordada nas páginas 1297 a 1302. 
- O crescimento da firma cooperada tende a ser bastante limitado e sua viabilidade pode ser severamente prejudicada caso os termos de financiamento de capital não sejam razoáveis;

A crise financeira internacional de 2008 serviu como bom experimento natural para que os economistas pudessem fornecer evidências adicionais para estas perguntas. Uma nova leva de estudos empíricos parece corroborar alguns fatos estilizados importantes: ao contrário das firmas capitalistas convencionais, as firmas cooperadas apresentaram maior estabilidade de emprego durante choques adversos de demanda. As firmas cooperadas também apresentaram políticas de investimentos bem diferentes das firmas capitalistas convencionais, uma vez que durante os períodos de boom pré-crise estas tenderam a acumular ativos, ao invés de aumentar a distribuição de dividendos entre acionistas, como comumente ocorre entre as firmas capitalistas convencionais (Delbono; Regiani, 2013; Navarra, 2013; Navarra, 2011; Burdin; Dean, 2009; ILO, 2009).

\section{A lógica da ação coletiva}

A teoria e os fatos estilizados discutidos na seção anterior mostram que as firmas cooperadas se comportam diferentemente das firmas capitalistas convencionais, buscando outros objetivos que não a maximização dos lucros da firma, inclusive evidenciando comportamentos ao longo dos ciclos econômicos que corroboram tal hipótese teórica, como é o caso de operar com curvas de oferta inelásticas e com coeficientes técnicos de produção (razões capital-trabalho) diferentes daqueles comumente utilizados entre as concorrentes capitalistas convencionais (maximizadoras de lucros).

Neste momento deve estar claro ao leitor que uma empresa (ou associações, cooperativas e agremiações) que opera nestes termos teria muita dificuldade de ser enquadrada na lógica da economia da colusão e dos cartéis. Por exemplo, imaginemos um mercado com $n$ empresas, das quais $n-1$ são firmas capitalistas convencionais e uma é uma firma cooperada, operando com uma curva de oferta perfeitamente inelástica. Imaginemos também que o mercado compete em quantidades (Cournot). Estaria claro para todos os $n$ concorrentes que a firma cooperada fixaria seu produto e emprego em um nível compatível com sua estratégia de maximização (que é diferente da estratégia das demais) e deixaria flutuar seu preço e market share de modo a manter estável seu nível de emprego e de produto.

Como é bem sabido da literatura econômica, o objetivo da colusão e da cartelização em Cournot é que todos os $n$ concorrentes fixem, de forma coordenada, quantidades inferiores àquelas observadas em equilíbrio de Cournot, de forma que o preço e a nova quantidade de mercado se alinhem aos níveis de um monopólio. Sem dúvida, cada um dos concorrentes receberia um lucro de monopólio partilhado 
superior àquele obtido em equilíbrio de Cournot. Contudo, também é sabido que cada um dos $n$ competidores teria incentivos para desviar do acordo estabelecido em cartel. A constituição de cartéis não é algo trivial por dois motivos: há fortes incentivos de desvio ${ }^{11}$ e o monitoramento do cartel é bastante complicado, inclusive para a identificar potenciais desviantes.

Aqui cabe destacar algumas perguntas: qual o incentivo para que $n-1$ empresas constituam cartel com uma empresa que, de partida, não estaria disposta a mudar seu emprego e produto, independentemente dos preços praticados no mercado? Mesmo que fosse aceita a condição de que (i) todas as $n-1$ firmas capitalistas convencionais teriam que reduzir mais do que proporcionalmente suas quantidades, absorvendo a parte da redução que caberia à firma cooperada; (ii) que o racionamento garantisse um preço que gerasse lucros maiores a todos, principalmente à firma cooperada, que verificou um aumento de preço para uma quantidade fixa e um market share maior; cabe perguntarmos se sob tais condições os incentivos ao desvio da cartelização não seriam ainda maiores? O monitoramento do cartel não seria ainda mais difícil?

Em termos práticos, isso significa que o cartel já seria constituído com uma empresa desviante. Em suma, a existência de firmas cooperadas pode até mesmo reduzir os incentivos ao comportamento que envolve condutas anticompetitivas. Neste ponto deve estar mais uma vez claro ao leitor que analisar as firmas cooperadas a partir do mesmo instrumental analítico dispensado às firmas capitalistas convencionais pode trazer sérias implicações, principalmente no âmbito da análise antitruste, em que as possibilidades de erros do Tipo I e do Tipo II não podem ser descartadas até mesmo quando da utilização de um instrumental analítico com alto grau de aderência.

Já que a lógica por trás da firma cooperada pode até mesmo trazer empecilhos à constituição de arranjos colusivos, cabe perguntar: por qual motivo as cooperativas ou associações de profissionais geralmente tomam atitudes similares a dos cartéis, ameaçando membros não dispostos a contribuir com o esforço de coordenação? Não seria isto uma evidência clara de tentativa de monopolização, inclusive com implicações como aumentos de preços e racionamento de fornecimento de bens ou serviços ao público, ao contrário do que sugere a teoria e a evidência da firma cooperada?

$\mathrm{Na}$ resposta para a primeira pergunta podemos utilizar o trabalho originalmente desenvolvido por Mancur Olson, em seu livro "The Logic of Collective Action: Public Goods and The Theory of Groups", cuja primeira edição foi impressa na língua inglesa em 1965. Olson (1999) endereça a dicotomia bem-

(11) O equilíbrio em cartel não é um equilíbrio de estratégias dominantes, assim como é o equilíbrio de Cournot. 
estar individual e bem-estar coletivo de forma bastante distinta daquela prescrita por Adam Smith. Para Smith, a "mão invisível" compatibilizava os interesses individuais e coletivos, de modo que se cada indivíduo racional buscasse a maximização de seu bem-estar, o resultado em termos coletivos seria o maior bem-estar da sociedade. Já Olson (1999) apontava para o fato de que, sob determinadas condições, na realidade, a busca individual racional maximizadora poderia trazer consequências bastante indesejáveis para o coletivo.

Não devemos imaginar que a constituição de firmas cooperadas (ou associações, cooperativas e agremiações) seja algo trivial. Uma das respostas para a sua baixa incidência é exatamente problemas relacionados à sua organização interna e a compatibilidade de incentivos e objetivos entre os cooperados (Dow; Putterman, 2000). A própria evidência empírica sugere que tais organizações tendem a ser mais promissoras, quanto menor a heterogeneidade entre os cooperados (Bonin Jones; Putterman, 1993).

Retomemos o problema da ação coletiva. Como o próprio título do livro de Olson (1999) sugere, toda a problemática da lógica da ação coletiva decorre de problema de bens públicos ou outras imperfeições de mercado ${ }^{12}$. A ideia central de Olson, como bem destacada por Hirschman (1994), é de que a lógica da ação coletiva "se baseia na ideia de que o ator racional é um free rider, um passageiro parasita, ou alguém que se furta da ação coletiva contando com o fato de que outros a farão em seu lugar, e assim acontece em cadeia, de modo que a ação coletiva ocorre muito raramente" (Hirschman, 1994, p. 93).

Para compreendermos melhor como se relacionam as noções de ação coletiva, problema de free rider e do motivo pelo qual a política antitruste deveria tratar diferentemente firmas capitalistas convencionais de firmas cooperadas, reportamos abaixo o Quadro 1, que busca sintetizar parte da problemática que será apresentada na sequência:

Quadro 1

Grupos, bens coletivos e incentivos do free rider

\begin{tabular}{|c|c|c|c|}
\hline $\begin{array}{l}\text { Tipo de } \\
\text { Grupo }\end{array}$ & Bem coletivo fornecido & Free Rider & Incentivo ao Free Rider \\
\hline $\begin{array}{l}\text { Sindicato de } \\
\text { Trabalhadores }\end{array}$ & $\begin{array}{l}\text { Estabilidade do produto e do } \\
\text { emprego. Melhores condições } \\
\text { de trabalho (inclui } \\
\text { remuneração). Imposição de } \\
\text { limites à discricionariedade } \\
\text { dos empregadores }\end{array}$ & $\begin{array}{c}\text { Trabalhador } \\
\text { não } \\
\text { sindicalizado }\end{array}$ & $\begin{array}{l}\text { Obtenção do bem coletivo } \\
\text { sem risco de retaliação por } \\
\text { parte do empregador; } \\
\text { Isenção de contribuição } \\
\text { sindical não pecuniária } \\
\text { (engajamento); }\end{array}$ \\
\hline
\end{tabular}

Continua...

(12) Decorre também de problemas de alocação de recursos comuns (Ostrom, 1990). 


\begin{tabular}{|c|c|c|c|}
\hline $\begin{array}{l}\text { Tipo de } \\
\text { Grupo }\end{array}$ & Bem coletivo fornecido & Free Rider & Incentivo ao Free Rider \\
\hline $\begin{array}{c}\text { Firmas } \\
\text { Cooperadas }\end{array}$ & $\begin{array}{l}\text { Estabilidade do produto e do } \\
\text { emprego. Melhores condições } \\
\text { de trabalho (inclui } \\
\text { remuneração). Ausência de } \\
\text { qualquer relação de } \\
\text { subordinação. }\end{array}$ & $\begin{array}{l}\text { Qualquer } \\
\text { cooperado. }\end{array}$ & $\begin{array}{l}\text { Obtenção do bem coletivo } \\
\text { exercendo um nível de } \\
\text { esforço de trabalho inferior } \\
\text { ao dos demais cooperados } \\
\text { (menor desutilidade de } \\
\text { trabalho para um mesmo } \\
\text { dividendo); }\end{array}$ \\
\hline $\begin{array}{l}\text { Cartel de } \\
\text { Empresas }\end{array}$ & $\begin{array}{c}\text { Lucros de monopólio } \\
\text { partilhados entre os membros, } \\
\text { que é superior aos lucros } \\
\text { individuais obtidos em } \\
\text { concorrência de Cournot }{ }^{(*)}\end{array}$ & $\begin{array}{c}\text { Qualquer } \\
\text { integrante do } \\
\text { cartel. }\end{array}$ & $\begin{array}{l}\text { O lucro individual de um } \\
\text { integrante que desvia do } \\
\text { acordo do cartel, ceteris } \\
\text { paribus, é superior ao lucro } \\
\text { de monopólio dividido e } \\
\text { que o lucro individual de } \\
\text { Cournot; }\end{array}$ \\
\hline
\end{tabular}

(*) Utilizamos o termo bem coletivo para não relacionar tais ações com a provisão de bens públicos.

A partir da lógica da ação coletiva e do problema de free rider, Olson (1999) sugere que o provimento do bem público não será viabilizado caso inexistam incentivos seletivos negativos sobre os free riders ou inventivos seletivos positivos aos participantes que contribuem com a viabilidade do fornecimento do bem coletivo. Os incentivos negativos são evidentemente formas de coerção e de discriminação, enquanto que os incentivos positivos incluem benefícios materiais (principalmente os benefícios obtidos com o poder de barganha do grupo, tais como planos de saúde mais baratos e empréstimos bancários a taxas de serviço e de juro menores, por exemplo) ou imateriais (orgulho e sentimento de pertencimento).

Aqui cabe um destaque quanto à análise antitruste de algumas situações envolvendo coerção entre grupos e free riders. $\mathrm{O}$ fato é que nem toda coerção a um free rider deveria fornecer evidência de cartelização. $\mathrm{Na}$ realidade, qualquer problema econômico que envolva provimento de bens públicos e consumo de recursos comuns, cuja solução envolva grupos, tenderá a apresentar a lógica da ação coletiva, o problema de free rider e o manuseio de incentivos negativos e positivos pelos grupos.

Isso significa dizer que a coerção por parte de associações de profissionais, cooperativas e sindicatos de trabalhadores a não membros (free riders) não é capaz de fornecer, isoladamente, evidência de potencial dano antitruste. Assumir tal hipótese equivaleria a sugerir que toda forma de ação coletiva carregaria algum dano antitruste e alguma perda de bem-estar para a sociedade. Por outro lado, também não é possível afirmar que toda iniciativa de associações de profissionais seja isenta de dano antitruste e esta é parte da resposta para a segunda questão abordada nesta seção. Contudo, uma resposta completa para a segunda questão implica conhecermos 
em maiores detalhes por qual motivo as firmas cooperadas (ou membros de associações profissionais ou cooperativas) se concentram.

\section{Barganha e poder compensatório}

Já que as firmas cooperadas apresentam características e objetivos diferentes das firmas capitalistas convencionais, principalmente no que diz respeito à maximização de lucros, uma pergunta óbvia a ser destacada é: por qual motivo há concentração de cooperados, associados e agremiações, que não pela busca de maximização de lucros por meio de coordenação? Segundo Worley et al. (2000), ao analisar o caso da indústria de aspargos no noroeste norte-americano, "as cooperativas de barganha são formadas e operam com o objetivo primário de providenciar poder de mercado compensatório para muitos pequenos produtores que vendem seus produtos a pequenos grupos de grandes compradores" (Worley et al., 2000, p. 548).

O reconhecimento do fato de que os modelos de firmas convencionais maximizadoras de lucros não representavam de forma apropriada as firmas cooperadas e a necessidade de uma teoria de cooperativa de barganha (concentração de cooperados) fez com que Ladd (1974) sugerisse um modelo teórico mais aderente às especificidades destes tipos de organizações, utilizando os seguintes termos:

Economists have many models of proprietary firms: profit maximizing models; constrained sales maximization models; utility maximization models; models for single-product firms and multi-product firms; models for purely competitive firms and monopolistic firms. Although cooperative firms are important in marketing agricultural products and supplying farm inputs, they are diverse in nature and operation, their objectives differ from those of proprietary firms, and they face some problems that proprietary firms do not face, there are few models of cooperative firms. The lack of well-developed models of cooperatives seriously restricts economists' ability to understand and predict cooperative behavior (Ladd, 1974, p. 509).

Podemos facilmente observar do parágrafo acima que o autor denomina de "proprietary firms" aquilo que até então temos denominado de firmas capitalistas convencionais. A diferença de terminologia pode ser atribuída a várias causas, mas a mais provável é que a literatura sobre diferenças de controle, propriedade e direitos residuais tem início a partir da década de 1980, enquanto que o texto de Ladd é de 1974.

Um fato bastante interessante é que o texto de Ladd (1974) já alertava na primeira metade da década de 1970 para a necessidade dos economistas não incorrerem no erro de tratar as firmas cooperadas como firmas capitalistas convencionais. Apontava ainda para o fato de que a ausência de instrumentos para uma melhor compreensão da lógica das firmas cooperadas poderia restringir 
seriamente a habilidade dos economistas em compreender e prever as consequências de tal comportamento.

Antes de avançarmos, cabe esclarecer qual o problema enfrentado em uma barganha pelas firmas cooperadas que não atinge as firmas capitalistas convencionais (além das eventuais assimetrias de poder). Na realidade, já discutimos este problema na seção anterior, mas acredito ser importante verificarmos que há quarenta anos algumas das discussões aqui abordadas já eram bastante claras para os teóricos das firmas cooperadas:

The public goods aspect of bargaining creates problems for bargaining cooperatives. Each member has an incentive to become a nonmember, for by doing so he can avoid the cost of supporting the bargaining while continuing to receive the higher price provided by the bargaining. Resulting declines in membership tend to increase the cooperative's cost per unit of member product handled and to reduce the cooperative bargaining effectiveness by reducing the supply of product under its management. Continued membership thus becomes less attractive to the remaining members (Ladd, 1974, p. 509).

O objetivo do presente artigo é exatamente apontar para o mesmo problema levantado por Ladd há quarenta anos. A diferença é que dispomos atualmente de muito mais recursos teóricos e empíricos, ou seja, estamos muito mais bem equipados que os economistas que antecederam Ladd. Contudo, o problema central é que a teoria e a prática de política antitruste ainda não trouxeram todo este conhecimento acumulado para o domínio da análise concorrencial.

Deve-se reconhecer que as questões de barganha assimétrica e de poder compensatório (originalmente desenvolvido por Galbraith, em 1952) têm sido abordadas na literatura sobre economia antitruste desde a segunda metade da década de 1990 (Ungern-Sternberg, 1996; Dobson; Waterson, 1997; Dobson; Waterson; Chu, 1998). No Brasil o tema ganhou maior visibilidade a partir dos trabalhos acadêmicos desenvolvidos por Azevedo e Almeida (Almeida, 2009; Azevedo; Almeida, 2009).

O ponto a ser discutido é por meio de qual lógica o tema barganha assimétrica e poder compensatório foi incorporado à análise antitruste. Ele não veio motivado por uma suposta diferença de incentivos e objetivos entre firmas capitalistas convencionais e firmas cooperadas, mas sim para fornecer resposta para a seguinte pergunta: Deveria a análise antitruste avaliar o poder de mercado do comprador diferentemente do poder de mercado do vendedor? (Schwartz, 2004).

$\mathrm{O}$ porto de partida dos autores que trataram originalmente este problema era a barganha upstream-downstream entre atacadistas e varejistas, mais especificamente sobre eventuais implicações da formação de um monopólio bilateral em termos de bem-estar, ou seja, (i) o bem-estar da sociedade seria prejudicado com 
concentrações que conduzissem para um monopólio bilateral por conta da "dupla marginalização"13? Ou (ii) uma eventual concentração em direção de um monopólio bilateral poderia trazer até mesmo ganhos de bem-estar por conta do poder compensatório?

A tese do poder compensatório serviu (explícita ou implicitamente) como argumento de eficiência econômica para a aprovação de um grande número de fusões e aquisições no setor varejista mundial, principalmente do segmento de supermercados, a partir da segunda metade da década de 1990. Este movimento ocorreu com grande força nos países do Hemisfério Norte e na América Latina (Gómez-Lobo; Gonzáles, 2009). A hipótese central era a de que a concentração dos varejistas, até então pulverizados, garantiria a redução da assimetria e o aumento do poder de barganha necessário para conquistar descontos junto aos seus fornecedores industriais, geralmente estruturados em setores altamente concentrados e oligopolizados. Cabendo ainda destacar que a redução da assimetria em tal barganha bilateral poderia ainda resultar em um equilíbrio de mercado similar ao de um monopolista verticalmente integrado, o que eliminaria dupla marginalização e poderia resultar - sob determinado conjunto de parâmetros - até mesmo na redução (ou no aumento) do preço (da quantidade ofertada) aos consumidores finais ${ }^{14}$.

Partir desta estrutura analítica para lidar com um problema de barganha entre uma firma capitalista convencional e um grupo de profissionais associados a uma cooperativa de barganha, cujo objeto é ofertar serviços de barganha para seus associados, não é um exercício trivial. Basicamente temos que assumir duas hipóteses, aqui denominadas de hipóteses de aderência: (i) a "dupla marginalização" é uma possibilidade crível; e (ii) uma situação de equilíbrio com barganha estável é possível.

A primeira hipótese de aderência estabelece que a firma cooperada "marginaliza", ao contrário do que foi observado da evidência disponível na literatura econômica teórica e empírica. Isso significa que o objetivo da firma cooperada seria a maximização dos lucros e não a estabilidade do emprego e do produto. Em suma, significaria dizer que a cooperativa de barganha opera como uma firma capitalista convencional. Tal possibilidade existe de fato, principalmente em casos de falseamento da atividade cooperada por parte de cartéis, porém a situação mais provável, tomando em consideração o que foi discutido nas seções anteriores, é que a firma cooperada tenha como objetivo de barganha a manutenção do nível de emprego e produto, associada a uma remuneração maior. Na prática ela não teria qualquer incentivo em usar o racionamento do fornecimento para aumentar artificialmente os preços, mas sim obter acréscimo de remuneração decorrente de

(13) Ver a discussão de "dupla marginalização" no Anexo ao fim do artigo.

(14) Idem nota de rodapé 10 
simples transferência de renda. Tal transferência pode ser interpretada economicamente como um montante fixo, como uma espécie de "contribuição privada" do tipo lump sum, que não traria maiores implicações para o custo marginal da firma capitalista convencional. Nestes termos, a operação envolveria apenas aspectos distributivos, sem qualquer implicação sobre eficiência e bem-estar. Em suma, o desejo é que as quantidades comercializadas permaneçam constantes e o aumento na remuneração da firma cooperada decorra apenas da transferência de lucros entre os diferentes elos da cadeia produtiva. Em suma, nos casos de cooperativas reais, a hipótese de aderência de "dupla marginalização" não parece ser verossímil.

A segunda hipótese de aderência requer que um monopólio bilateral de firmas capitalistas convencionais, um monopólio bilateral com uma firma capitalista convencional e uma firma cooperada alcancem o mesmo resultado prático. Contudo, não basta que a mesma simetria seja alcançada no que diz respeito ao poder de mercado, faz-se necessário que esta situação de equilíbrio seja estável para que as cláusulas do contrato barganhado sejam cumpridas ex post. Para que isso seja possível, a firma cooperada deverá contornar o problema de ação coletiva e dispor de uma opção de retirada (fallback position) tão desejável quanto à do oponente na barganha.

O problema é que a opção de retirada do oponente - uma firma capitalista convencional - é a realocação do capital em qualquer outra aplicação (atividade) alternativa, que ao menos cubra seu custo de oportunidade. Por exemplo: retirá-lo dos serviços de saúde e direcioná-lo para os serviços de educação. Como o capital é muito mais fluído que os serviços profissionais, sejam em termos de aplicação em atividades alternativas ou em termos geográficos, a redução de assimetria das opções de retirada - que afeta diretamente a assimetria da barganha - não parece ser um resultado factível. Novamente, nos casos de cooperativas de fato, a hipótese de aderência de equilíbrio com barganha estável não parece ser verossímil.

Em termos gerais, pode-se inferir que a discussão de poder compensatório só faria sentido na análise de uma barganha envolvendo uma firma capitalista convencional e uma cooperativa que não opera nos moldes da firma cooperada estudada ao logo do presente trabalho (o que inclui cartéis disfarçados de cooperativas) ${ }^{15}$.

(15) De fato, os proponentes da aplicação da teoria do poder compensatório nos casos envolvendo condutas de cooperativas não contestam o argumento de que as estratégias e as motivações econômicas das cooperativas e das seguradoras sejam exatamente as mesmas (maximização dos lucros). A única assimetria apontada diz respeito ao poder de barganha decorrente das diferenças nas respectivas concentrações de mercados. 


\section{Implicações para política antitruste}

Neste ponto deve estar claro ao leitor que as motivações das firmas cooperadas são muito distintas das motivações de um sindicato de trabalhadores. Ao contrário do caso da firma cooperada, os trabalhadores de uma firma capitalista convencional não exercem qualquer controle sobre a firma, muito pelo contrário, há uma relação de subordinação e este é um dos motivos pelos quais os sindicatos de trabalhadores gozam de isenção antitruste. Por outro lado, os objetivos da firma cooperada diferem de todos aqueles que norteiam a ação da firma capitalista convencional e, por conta disto, não parece prudente avaliar suas ações tomando como base um referencial analítico pouco aderente. Em termos de política antitruste, a conclusão que podemos extrair do presente artigo é de que uma concentração ou coordenação entre profissionais não é, per se, condição necessária e suficiente para causar dano antitruste. As especificidades e idiossincrasias destes tipos de organizações sugerem análise específica e a aplicação da regra da razão por parte das autoridades antitruste

Como mencionado na introdução do presente artigo, um dos principais desafios das autoridades antitruste ao redor do mundo é julgar casos de conduta nos mercados de saúde suplementar, principalmente os casos que envolvem condutas anticompetitivas por parte de associações e cooperativas de profissionais médicos. Também foi discutida na introdução a necessidade do aprimoramento de uma metodologia de filtro econômico comportamental para melhor identificação e distinção de situações nas quais uma agremiação de profissionais está operando como uma organização cooperada, ou se na realidade trata-se de um cartel disfarçado de cooperativa.

Ainda na introdução do presente artigo foi mencionado que muitos dos casos levados às autoridades de concorrência, nos quais recaiam suspeitas sobre a conduta anticompetitiva por parte de associações ou cooperativas de profissionais, envolvem tanto questões de lide privada, quanto o falseamento da atividade cooperada por parte de cartéis.

Os casos levados para as autoridades envolvendo a participação de firmas cooperadas de fato são claramente relacionados a problemas de lide privada, que sequer deveriam ser submetidos à análise da autoridade antitruste. Contudo, não é uma tarefa trivial identificar e distinguir motivações de lide privada com reais motivações anticoncorrenciais. Neste sentido, a literatura da firma cooperada pode trazer grande contribuição para identificação por meio de filtros comportamentais. Sabemos que as firmas cooperadas partilham das seguintes características:

- As firmas cooperadas tendem a buscar a manutenção da estabilidade do emprego e do produto em face às variações de preços e demais choques, ou seja, operam com uma curva de oferta praticamente inelástica; 
- Tendem a operar com razões capital-trabalho inferiores àquelas observadas nas firmas capitalistas convencionais;

- Tendem a ocorrer em ondas com períodos de duração inferiores aos dos ciclos econômicos; uma vez estabelecidas e em operação, tendem a ser mais resistentes;

- Surgem motivadas pela proteção e manutenção do emprego ou são constituídas para providenciar um ambiente no qual a interação entre os trabalhadores seja cooperativa e não alienante;

- Seu crescimento é bastante limitado e sua viabilidade pode ser severamente prejudicada caso os termos de financiamento de capital não sejam razoáveis;

A observação de algumas das características acima listadas ${ }^{16}$, associadas a outras provas não econômicas disponíveis nos autos dos processos de conduta, podem sugerir que a motivação de uma eventual denúncia contra a cooperativa tenha sido decorrente de um problema de lide privada.

Já a ausência das características acima sugere que seja afastada a hipótese de envolvimento de uma firma cooperada de fato. O mais comum nestes casos é que a cooperativa esteja agindo como uma firma capitalista convencional, ou seja, buscando maximização de lucros por meio de seu poder de mercado e racionando a oferta de bens e serviços para elevar artificialmente os preços, caso isso seja economicamente factível para alcançar seus objetivos. Nestes casos faz sentido para a autoridade antitruste considerar a tese de poder compensatório ${ }^{17}$ para inferir se a barganha centralizada dos profissionais pode gerar eficiências econômicas, ao invés de aumento de preços ao consumidor decorrente de dupla marginalização. Contudo, a tese de poder compensatório tem sido recebida com pouco entusiasmo pelas autoridades antitruste para os casos de conduta de cartel.

De fato, a autoridade antitruste estará mais exposta a cometer um Erro do Tipo I (julgar o réu culpado, quando na realidade é inocente) ao dispensar a hipótese de que firmas cooperadas se comportam diferentemente de firmas capitalistas convencionais, do que dispensar a hipótese de poder compensatório.

(16) Em termos práticos, a estimativa da elasticidade-preço da oferta da cooperativa em análise já poderia fornecer alguma informação relevante acerca de sua estratégia de negócios. Em suma: uma elasticidade-preço da oferta próxima de zero tenderia a corroborar a hipótese de que a cooperativa em questão não opera nos moldes de um cartel.

(17) A tese de poder compensatório tem sido utilizada de forma muito limitada na atuação do Cade. Um número muito reduzido de conselheiros tem considerado tal tese. Mesmo assim, quando utilizada, tem servido mais como um atenuante para a fixação da multa administrativa nos casos de punição, do que para absolvição das cooperativas. Contudo, mesmo os votos que utilizam a tese do poder compensatório para atenuar multas administrativas acabam sendo vencidos nas decisões do colegiado. 


\section{Considerações finais}

O presente artigo apresentou e discutiu os desdobramentos e avanços da literatura econômica acerca das firmas cooperadas e suas diferenças fundamentais em relação ao comportamento das firmas capitalistas convencionais. A ideia do artigo foi abordar o tema sob a ótica da política da competição e apontar para o fato de que o tratamento analítico antitruste despendido para a firma capitalista convencional só será satisfatoriamente aplicado para o caso da firma cooperada em condições bem específicas. Foi apontado ainda que o uso de referencial analítico com baixa aderência para a análise de atos de concentração e de conduta envolvendo firmas cooperadas pode aumentar significativamente as probabilidades de ocorrência de Erro do Tipo I (julgar o réu culpado, quando na realidade é inocente) e Erro do Tipo II (julgar o réu inocente, quando na realidade é culpado).

As diferenças entre as firmas capitalistas convencionais e as firmas cooperadas são apontadas tanto em seus aspectos teóricos, quanto em seus aspectos empíricos. No campo da teoria, os modelos econômicos da firma capitalista convencional e da firma cooperada divergem no que diz respeito à variável de escolha para maximização (maximizando): enquanto a firma capitalista convencional busca a maximização de lucros, a firma cooperada busca a maximização dos dividendos per capita. Os primeiros modelos de firma cooperada encontravam soluções de equilíbrio com curvas de oferta negativamente inclinadas - o que seria uma ineficiência deste tipo de firma e justificaria a supremacia da firma capitalista - mas as sofisticações do modelo original alcançaram soluções de equilíbrios mais condizentes com os fatos estilizados da literatura.

No campo das evidências empíricas foi visto que as firmas cooperadas tendem a buscar a manutenção da estabilidade do emprego e do produto em face às variações de preços e demais choques, ou seja, operam com uma curva de oferta praticamente inelástica; tendem a operar com razões capital-trabalho inferiores àquelas observadas nas firmas capitalistas convencionais; tendem a ocorrer em ondas com períodos de duração inferiores aos dos ciclos econômicos; uma vez estabelecidas e em operação, tendem a ser mais resistentes; surgem motivadas pela proteção e manutenção do emprego ou são constituídas para providenciar um ambiente no qual a interação entre os trabalhadores seja cooperativa e não alienante; seu crescimento é bastante limitado e sua viabilidade pode ser severamente prejudicada caso os termos de financiamento de capital não sejam razoáveis.

Já no que diz respeito à discussão acerca de política antitruste, foi visto que o incentivo da firma cooperada em buscar a estabilidade do emprego e do produto faz com que uma eventual competição em oligopólio (com outras firmas capitalistas convencionais como concorrentes) apresente limitações ainda maiores para a constituição de eventual cartel. O problema é que todas as firmas capitalistas teriam 
que racionar suas quantidades mais do que proporcionalmente para assegurar o desejo de estabilidade do emprego e produto da firma cooperada. Na prática, isso equivaleria a instalar um cartel já tendo como certo que uma empresa desviaria do equilíbrio coordenado, o que dificilmente viabilizaria a execução do ilícito, principalmente no que diz respeito ao monitoramento do cartel. Em suma, a existência de firmas cooperadas pode até mesmo reduzir os incentivos ao comportamento anticompetitivo.

Foram analisados ainda os determinantes da concentração da firma cooperada. A evidência disponível na literatura econômica sugere que tais concentrações são motivadas com objetivos de bargaining leverage e exercício de poder compensatório em negociações envolvendo monopólios bilaterais. Neste ponto foi discutido que a hipótese de risco de "dupla marginalização" deve ser abordada com cautela pela autoridade antitruste ao analisar situações envolvendo firmas cooperadas. Novamente foi alertado que utilizar o mesmo referencial analítico aplicado em monopólios bilaterais de firmas capitalistas convencionais pode ser inadequado. Isso ocorre por conta do fato de dispormos de pouca evidência teórica e empírica na literatura especializada que justifique um comportamento "marginalizante" por parte das firmas cooperadas.

Foi discutido que a possibilidade de "dupla marginalização" em um monopólio bilateral, com ao menos uma firma cooperada, não deve ser descartada, porém a situação mais provável é que a firma cooperada upstream, por exemplo, tenha como objetivo de barganha a manutenção do nível de emprego e do produto, mas com uma remuneração maior. Partindo de uma situação na qual as quantidades comercializadas permaneçam constantes, o aumento de preço upstream implicaria apenas na transferência de quasi-rendas entre os elos da cadeia produtiva, ou seja, limitar-se-ia a um problema distributivo, sem maiores consequências em termos de eficiência e de bem-estar. Mesmo que a firma cooperada busque a maximização de lucros, não poderíamos descartar que o potencial exercício de poder compensatório implique no aumento de bem-estar, como é usualmente discutido na literatura antitruste.

Em termos de política pública, a conclusão que podemos extrair do presente artigo é de que uma concentração ou coordenação entre profissionais não é, per se, condição necessária e suficiente para causar dano concorrencial. As especificidades e idiossincrasias destes tipos de organizações sugerem análise específica e a aplicação da regra da razão por parte das autoridades antitruste. Finalmente, a partir das informações obtidas na literatura especializada acerca dos comportamentos teórico e empírico das empresas cooperadas, o presente artigo prescreve uma proposta de filtro comportamental para distinção entre firmas cooperadas de fato e cartéis disfarçados de cooperativas. Tal contribuição pode ser de grande valia para as autoridades da concorrência, pois o que pode ser inferido ao longo do presente 
trabalho é que estas estariam mais expostas a cometer um Erro do Tipo I (julgar o réu culpado, quando na realidade é inocente) ao dispensar a hipótese de que firmas cooperadas se comportam diferentemente de firmas capitalistas convencionais, do que dispensar a hipótese de poder compensatório (o que tem sido a prática das autoridades).

\section{Bibliografia}

ABRAHAM, M.; PROSCH, B. Long-term employment relationships by credible commitments: the Carl Zeiss Foundation. Rationality \& Society, v. 12, n. 3, p. 283306, 2000.

ALMEIDA, S. Poder compensatório e política da defesa da concorrência: referencial geral e aplicação ao mercado de saúde complementar brasileiro. Brasília, DF: IV Prêmio SEAE, 2009.

AZEVEDO, P.; ALMEIDA, S. Poder compensatório: coordenação horizontal na defesa da concorrência. Estudos Econômicos, v. 39, n. 4, p. 737-762, 2009.

BLANCHFLOWER, D.; OSWALD, A.; SANFEY, P. Wages, profits and rentsharing. National Bureau of Economic Research, Inc., 1992. (NBER Working Papers, 4222).

BONIN, J.; FUKUDA, W. The multi-factor Illyrian firm revisited. Journal of Comparative Economics, v. 10, n. 2, p. 171-180, 1986.

; JONES D.; PUTTERMAN, L. Theoretical and empirical studies of producer cooperatives: will ever the twain meet? Journal of Economic Literature, v. 31, p. 1290-1320, 1993.

BOWLES, S. The production process in a competitive economy: Walrasian, NeoHobbesian, and Marxian Models. American Economic Review, v. 75, n. 1, p. 16-36, 1985.

; GINTIS, H. A political and economic case for the democratic enterprise. Economics and Philosophy, 9, p. 75-100, 1993.

BRASIL. Ministério da Saúde. Glossário Temático: saúde suplementar. Brasília, DF: Agência Nacional de Saúde Suplementar, 2009.

BURDIN, G.; DEAN, A. New evidence on wages and employment in workers cooperatives compared with capitalist firms. Journal of Comparative Economics, v. 37, n. 4, p. 517-533, 2009.

CADE. Mercado de Saúde Complementar: Condutas. Cadernos do CADE, Brasília, DF, 2015. 
DELBONO, F.; REGIANI, C. Cooperative firms and the crisis: evidence from some Italian mixed oligopolies. Annals of Public and Cooperative Economics, v. 84, n. 4, p. 383-397, 2013.

DOBSON, P.; WATERSON, M. Countervailing power and consumer prices. The Economic Journal, 107, p. 418-430, Mar. 1997.

; CHU, A. The welfare consequences of the exercise of buyer power. Office of Fair Trading Research Paper, 16, p. 1-55, 1998.

DOMAR, E. The Soviet collective farm as a producers' cooperative. American Economic Review, v. 56, n. 4, p. 734-757, 1966.

DOW, G. Control rights, competitive markets, and the labor management debate. Journal of Comparative Economics, v. 10, n. 1, p. 48-61, 1986.

. Why capital hires labor: a bargaining perspective. American Economic Review, v. 83, n. 1, p. 118-134, 1993.

; PUTTERMAN, L. Why capital suppliers (usually) hire workers: what we know and what we need to know. Journal of Economic Behavior \& Organization, 43, p. 319-336, 2000.

DRÈZE, J. Some theory of labor management and participation. Econometrica, v. 44, n. 6, p. 1125-1139, 1976.

Markets for membership in the labor-managed firm: a simple general equilibrium model. University of Alberta. Department of Economics, 1989. (Unpublished Manuscript).

GALBRAITH, J. American capitalism: the concept of countervailing power. Boston, MA: Houghton Mifflin, 1952.

GOLDBERG, D. Antitruste e a barganha coletiva no mercado de saúde suplementar. Revista de Direito da Concorrência, 9, p. 329-355, 2006.

GÓMEZ-LOBO, A.; GONZÁLEZ, A. Mergers, prices and concentration in the supermarket industry: the case of Chile. In: FOX, E. (Ed.). Competition law and policy in Latin America. Hart Publishing, 2009. p. 391-411.

HARRINGTON, J. Detecting cartels. In: BUCCIROSSI, P. (Ed.). Handbook of antitrust economics. MIT Press, 2008. p. 213-258.

HART, O. Firms, contracts, and financial structure. Oxford: Clarendon Press, 1995.

HILDRETH, A.; OSWALD, A. Rent-sharing and wages: evidence from company and establishment panels. Journal of Labor Economics, v. 15, n. 2, p. 318-337, 1997. 
HIRSCHMAN, A. A moral secreta do economista. São Paulo, SP: Editora Unesp, 1994.

HSIAO, W. Abnormal economics in the health sector. Health Policy, v. 32, n. 5, p. 125-139, 1995.

ILO. Resilience of the cooperative business model in times of crisis. Sustainable Enterprise Programme. Italy: ILO, 2009.

IRELAND, N.; LAW, P. Efficiency incentives, and individual labor supply in the labor-managed firm. Journal of Comparative Economics, v. 5, n. 1, p. 1-23, 1981.

KATZ, L. Efficiency wage theories: a partial evaluation. 1986. (NBER Working Papers, 1906).

LADD, G. A model of a bargaining cooperative. American Journal of Agriculture Economics, v. 56, p. 509-519, 1974.

LEONARD, J. Carrots and sticks: pay, supervision, and turnover. Journal of Labor Economics, v. 5, n. 4, p. S136-S152, 1985.

MEADE, J. The adjustment processes of labour co-operatives with constant returns to scale and perfect competitive. The Economic Journal, v. 82, p. 402-428, 1972.

NAVARRA, C. Profit reinvestment in Italian worker cooperatives as a contribution to a common good: an empirical analysis on workers' perception and motivation. In: DE VARO, J.; TAKAO, K. (Ed.). Advances in the economic analysis of participatory and labor-managed firms. UK: Emerald, 2011. v. 12, p. 199-229.

How do worker cooperatives stabilize employment? The role of profit reinvestment into locked assets. Department of Economics University of Namur, 2013. (Working Paper, n. 1307).

OLSON, M. The logic of collective action: public goods and the theory of groups. Boston, MA: Harvard University Press, 1999.

OSTROM, E. Governing the commons: the evolution of institutions for collective action. Boston, MA: Cambridge University Press, 1990.

REBITZER, J. Unemployment, long-term relationship employment relations, and productivity growth. The Review of Economics and Statistics, v. 69, n. 4, p. 627$635,1987$.

SAMUELSON, P. Wages and interest: a modern dissection of Marxian economics. American Economic Review, v. 47, p. 884-912, 1957.

SCHWARTZ, M. Should antitrust assess buyer market power differently than seller market power? Washington, DC: DOJ/FTC Workshop on Merger Enforcement, 2004. 
SHAPIRO, C.; STIGLITZ, J. Unemployment as a worker discipline device. American Economic Review, v. 74, n. 3, p. 433-444, 1984.

UNGERN-STERNBERG, T. Countervailing power revisited. International Journal of Industrial Organization, v. 14, p. 507-520, 1996.

VANEK, J. The general theory of labor-managed market economies. Ithaca, NY: Cornell U. Press, 1970.

WARD, B. The firm of Illyria: market syndicalism. American Economic Review, v. 48, p. $566-589,1958$.

WILLIAMSON, O. The economic institution of capitalism: firms, markets, relational contracting. New York, NY: Free Press, 1985.

WORLEY, T.; FOLWELL, R.; FOLTZ, J.; JAQUA, A. Management of a cooperative bargaining association: a case in the Pacific Northwest Aspargus Industry. Applied Economic Perspectives and Policy, v. 22, n. 2, p. 548-565, 2000. 


\section{Anexo}

\section{“Dupla Marginalização" e Barganha Upstream-Downstream}

Imaginemos uma situação na qual tenhamos um monopolista atacadista upstream, que pratica um preço unitário igual a $p^{U}$ e incorre em um custo marginal de produção constante igual a $c$. Sua demanda é determinada pelo mercado varejista downstream, que é formado por $n$ firmas varejistas simétricas, cujo custo marginal de produção equivale ao preço unitário upstream, com cada uma produzindo uma quantidade igual a $q_{i}$, de modo que a demanda total do monopolista atacadista upstream é igual a $Q=\sum q_{i}$. O preço de varejo dowsntream é igual a $p^{D}$ e sua demanda será igual a $D\left(p^{D}\right)=a-b p^{D}$.

O objetivo aqui é duplo: (i) determinar o significado de "dupla marginalização"; e (ii) mostrar como a barganha upstream-downstream pode mitigar o problema da "dupla marginalização". Para compreendermos a noção de "dupla marginalização" vejamos como são determinadas as quantidades, os preços e os lucros do monopolista atacadista upstream e das $n$ firmas varejistas downstream. A partir da demanda downstream, podemos obter a seguinte expressão:

$$
p^{D}=\frac{a-Q}{b}
$$

Já a equação de lucro downstream do varejista $j$ pode ser especificada como:

$$
\pi_{j}=\frac{a-Q}{b} q_{j}-p^{U} q_{j}
$$

Derivando a equação [A.2] em relação à $q_{j}$ e sabendo que $Q=q_{1}+q_{2}+\cdots+q_{j}+$ $\cdots+q_{n}$, temos a seguinte condição de primeira ordem:

$$
\frac{\partial \pi_{j}}{\partial q_{j}}=\frac{a-Q}{b}+q_{j}\left(\frac{-1}{b}\right)-p^{U}=0
$$

Considerando a hipótese de simetria entre as $n$ firmas varejistas, temos a seguinte solução para a condição de primeira ordem:

$$
p^{U}=\frac{a-n q-q}{b}
$$

A quantidade de equilíbrio para cada uma das $n$ firmas varejistas downstream será:

$$
q=\frac{a-b p^{U}}{n+1}
$$

A equação de lucro do monopolista atacadista upstream será igual a:

$$
\pi^{U}=\left(p^{U}-c\right) Q=\frac{n}{n+1}\left[\left(p^{U}-c\right)\left(a-b p^{U}\right)\right]
$$

Diferenciando a equação [A.6] em relação à $p^{U}$, obtemos a condição de primeira para o lucro do monopolista atacadista upstream: 


$$
\frac{\partial \pi^{U}}{\partial p^{U}}=\left(p^{U}-c\right)(-b)+\left(a-b p^{U}\right)=0
$$

A solução de equilíbrio para o preço upstream é igual a:

$$
p^{U}=\frac{a+b c}{2 b}
$$

Substituindo [A.8] em [A.5] encontramos a quantidade de equilíbrio para cada uma das $n$ firmas varejistas downstream:

$$
q=\frac{a-b c}{2(n+1)}
$$

Já a quantidade total de equilíbrio no mercado downstream é igual a:

$$
Q=\frac{n(a-b c)}{2(n+1)}
$$

O preço de equilíbrio no mercado downstream é igual a:

$$
p^{D}=\frac{a}{b}-\frac{n(a-b c)}{2 b(n+1)}
$$

O lucro de cada uma das $n$ firmas varejistas downstream será igual a:

$$
\pi_{j}=\frac{(a-b c)^{2}}{4 b(n+1)^{2}}
$$

Podemos verificar da equação [A.12] que, quando o número de empresas varejistas downstream tende ao infinito $(n \rightarrow \infty)$, o lucro de cada uma delas tenderá a zero $\left(\pi_{j} \rightarrow 0\right)$, ou seja, o preço do varejo igualaria ao preço do atacado.

Já o lucro do monopolista atacadista upstream será igual a:

$$
\pi_{m}=\frac{n(a-b c)^{2}}{4 b(n+1)}
$$

Consideremos agora que o monopolista atacadista upstream integralize verticalmente toda a cadeia. O problema do monopolista será maximizar a seguinte expressão abaixo:

$$
\max _{Q}\left(\frac{a-Q}{b}\right) Q-c Q
$$

Cujas soluções para quantidade e preço de equilíbrio são:

$$
Q=\frac{(a-b c)}{2} \quad, \quad p^{U}=\frac{a+b c}{2 b}
$$

O leitor perceberá que o equilíbrio de cadeia verticalmente integrada é compatível com uma solução onde $n \rightarrow \infty$. Em suma, qualquer $n<\infty$ fará com que o preço do varejo seja superior ao preço de atacado praticado por um monopolista verticalmente integrado. Este fenômeno é denominado na literatura econômica como "dupla marginalização". 
Com $n=1$, a "dupla marginalização" tende a ser a maior possível, porém o problema da "dupla marginalização" neste monopólio bilateral pode ser evitado em uma barganha em que, por exemplo, o monopolista upstream vende ao monopolista downstream seu produto ao preço igual ao custo marginal, mas cobra um montante adicional fixo (lump sum) a título de franquia, $F$.

Nestas circunstâncias, o monopolista varejista downstream buscará maximizar seu lucro a partir da seguinte equação:

$$
\max _{Q}\left(\frac{a-Q}{b}\right) Q-F-c Q
$$

Como $F$ é uma constante a ser paga ao monopolista upstream, as soluções de equilíbrio obtidas a partir das condições de primeira ordem para [A.16] são as mesmas que verificamos em [A.15]. Sabemos também que tais condições de equilíbrio são análogas àquelas obtidas quando $n \rightarrow \infty$. O valor de $F$ a ser barganhado é o maior possível, pois equivale ao lucro do monopolista integrado:

$$
F=\frac{(a-b c)^{2}}{4 b}
$$

Uma vez que não podemos encontrar lucro maior, este contrato de barganha sobre $F$ trará uma solução de ótimo de Pareto. 